Türkiye Tarımsal Araştırmalar Dergisi
http://dergi.siirt.edu.tr $\begin{aligned} & \text { Turk J Agric Res } \\ & \text { (2015) 2: 69-75 } \\ & \text { TÜTAD } \\ & \text { ISSN: 2148-2306 }\end{aligned}$

\title{
Siirt İlinde Çayır Mera Alanlarından ve Yem Bitkilerinden Elde Edilen Kaba Yem Üretim Potansiyeli
}

\author{
Nizamettin TURAN ${ }^{1 *}$, Mehmet Arif ÖZYAZICI ${ }^{1}$, Gülcan YALÇIN TANTEKİN ${ }^{2}$ \\ ${ }^{I}$ Siirt Üniversitesi, Ziraat Fakültesi, Tarla Bitkileri Bölümü, Siirt, TÜRKIYE \\ ${ }^{2}$ Diyarbakır Büyükşehir Belediyesi, Diyarbakır, TÜRKIYE
}

Geliş Tarihi/Received: 09.03.2015

Kabul Tarihi/Accepted: 27.03.2015

*Sorumlu Yazar/Correspondence: nturan49@siirt.edu.tr

Özet: Siirt ilinin coğrafik yapısından dolayı halkın önemli bir kesiminin geçim kaynağı hayvancılık ve bitkisel üretime dayanmaktadır. Hayvancılık genellikle çayır-mera hayvancılı̆̆ şeklinde yapılmaktadır. Hayvansal üretimde vazgeçilmeyen en önemli yem grubunu kaba yemler oluşturmaktadır. Hâlihazırda Siirt ilinde çayır mera kaynaklı üretilen kuru ot miktarı 130.461 ton, yem bitkileri kaynaklı kuru ot miktarı 60.177 ton civarındadır. Buna karșılık Siirt ilinde 101.899 büyük baş hayvan birimine eşdeğer hayvan varlığı bulunmaktadır. Bu hayvanların yıllık ortalama yaşama payı için kaba yem ihtiyacı ise 464.914 tondur. İlin doğal çayır mera alanlarından ve yem bitkileri ekilişlerinden elde edilen toplam kaba yem üretimi 190.638 ton olup, sahip olduğu hayvan varlığının ancak \% 41'ine yetecek kadardır. Bu nedenle mevcut çayır mera alanlarında üretimi arttırmak için, amenajman tekniklerine uyulmalı ve sslah çalışmalarına hız verilmelidir. Ayrıca, yem bitkileri ekim alanları arttırılmalı, özellikle nadasa bırakılan alanlarda ekim nöbeti sistemleri geliştirilerek yem bitkileri tarımına öncelik verilmelidir.

Anahtar Kelimeler: Siirt, çayır, mera, yem bitkileri, hayvan varlı̆̆ı

\section{Production Potential of Fodder Obtained from the Meadow-Rangelands and Forage Crops Fields in Siirt Province}

\begin{abstract}
Due to the geographical structure of Siirt Province, mainstay of a significant part of the population is based on livestock and crop production. Livestock is usually carried out in the form of meadows-pastures livestock. The most essential feed group in animal production is forage. At present, the dry hay amount provided from meadow-rangelands and forage crops are 130.461 and 60.177 tonnes, respectively. On the other hand, there are 101.899 of animal existence equivalent to livestock unit in Siirt. The fodder requirements of these animals are 464.914 tons per year. Total fodder production of province from natural meadow-range areas and forage crop cultivation is 190.638 tonnes but this is enough for $41 \%$ of animal existence. Therefore, management techniques must be followed and should be accelerated to the breeding studies to increase productivity in existing meadow-rangelands. Besides, cultivation area of forage crops should be increased and the crop rotation systems must be developed and priority should be given to forage crops within the crop rotation system particularly in fallow areas.
\end{abstract}

Keywords: Siirt, meadow, range, forage crops, animal existence

\section{Giriş}

Ülkemiz hayvancılığının en önemli sorunlarından biri yeterli miktarda kaliteli kaba yem üretilememesidir. Kaliteli kaba yemler, doğal çayır ve mera alanları ile yem bitkileri tarımı olmak üzere iki önemli kaynaktan sağlanmaktadır. Çayır ve meralar, hayvanların ihtiyacı olan kaba yemin en ucuz karşılandığı alanlar olma özelliğinin yanında; doğal bitki örtüsü ile biyolojik çeşitlilik göstermesi; birçok kültür bitkisi için gen kaynağ 1 
olarak kullanılabilecek yabani akrabalarını bünyesinde barındırması; yine birçok tıbbi bitkinin kaynağını teşkil etmesi; ilkel canlılardan yaban hayvanlarına kadar çok çeşitli canlıların yaşam alanı, yem kaynağı, doğal barınak ve üreme alanları olması; toprak verimliliğinin artmasında ve toprakların yerinde tutulmasinda, su kaynaklarının muhafazasında ve geliştirilmesinde önemli role sahip olması; gezinti, eğlence ve turizm alanları olması gibi birçok niteliklere sahiptir (Açıkgöz, 2001). Türkiye'de 14.6 milyon hektar olan çayır ve mera arazilerinin (Anonim, 2015a); birçok bölgemizde uzun yıllardır devam eden aşırı, zamansız ve bilinçsiz otlatma yanında, bakım işlerinin yapılamaması ve drenaj sorunları gibi nedenlerle verim güçleri yitirilmekte (Yulafçı ve Pul, 2005; Yolcu ve Tan, 2008; Alçiçek ve ark., 2010; Sayar ve ark., 2010; Altın ve ark., 2011; Kuşvuran ve ark., 2011; Temel ve Şahin, 2011; Budak, 2013), hayvanlar tarafindan sevilerek yenen iyi cins yem bitkisi türleri sürekli azalmakta, birçok alanlarda yok olmaktadır.

Bitkisel ve hayvansal üretimin sigortası konumundaki yem bitkileri tarımı, tarımsal üretimde önemli bir yere sahip olup, sürekli ve güvenli kaba yem üretiminin en önemli yoludur (Açıkgöz, 2001; Açıkgöz ve ark., 2005). Ülkemiz toplam tarım alanı nadas alanları da dâhil 23.811 bin hektardır. 1990'lı yılların başında toplam tarım alanı içerisindeki yem bitkileri ekiliş oranı \% 3.9 civarında iken, son yıllardaki yem bitkileri desteklemelerine paralel olarak bu oran günümüzde \% 11.1'lere çıkmıştır (Anonim, 2015b). Yem bitkilerine sağlanan desteklemelerle elde edilen bu olumlu gelişmelere rağmen, hala gerek ülkemizde ve gerekse Siirt yöresinde yem bitkilerinin toplam ekiliş içerisindeki payı, hayvanların kaliteli kaba yem ihtiyacını karşılamaktan uzaktır. Yörede yem bitkileri tarımının istenilen düzeyde olmamasında; üreticilerin yem bitkileri tarımı konusunda yeterli bilgiye sahip olmaması, toprak işleme, ekim, gübreleme ve biçim gibi uygulamalarda ciddi hatalar yapılması (Kara ve ark., 2009), etkili olmaktadir.

Hayvansal üretimi etkileyen faktörlerin başında ıslah, pazarlama, araştırma, besleme, bakım ve idare gelmektedir. Ancak, bunların en önemlisini kaliteli kaba yem üretimi oluşturmaktadır. Diğer koşullar ne kadar iyi olursa olsun, yetersiz beslenme koşulları altında hayvansal üretimden istenilen başarıya ulaşmak mümkün değildir.

Tarımsal araştırma ve yayım çalışmalarının başarıya ulaşması adına, yöresel olarak kaba yem üretimi projeksiyonlarının ortaya konması, problemlerin irdelenerek mevcut durum analizinin yapılması, belirlenen sorunlara ilişkin çözüm önerilerinin geliştirilmesi, araştırma ve yayım faaliyetlerinin planlanması açısından önem taşımaktadır. Bu derleme çalışmasında, Siirt ilinde kaba yem üretimi, mevcut hayvanlarımıza yeterlilik durumu, sorunları ve çözüm önerileri üzerinde durulmuştur.

\section{Siirt İli Arazi Varlığı ve Kullanım Durumu}

Mezopotamya ve Anadolu uygarlıklarının kesiştikleri alanda kurulu olan Siirt ili, 41 ${ }^{\circ} 57^{\prime}$ doğu boylamı ve $37^{\circ} 55^{\prime}$ kuzey enlemi üzerinde bulunmakta olup, il kuzeyden Batman ve Bitlis, batıdan Batman, güneyden Mardin ve Şırnak, doğudan Şırnak ve Van illeri ile çevrilidir.

Siirt ilinde genellikle karasal iklim hâkimdir. Doğu ve kuzey bölgelerinde kışlar daha sert ve yağışl1, güney ve güneybatı bölgelerinde ise kışın 1lık iklimine karşılık yazlar daha sıcak ve kuraktır. Ortalama yıllık yağış miktarı $700 \mathrm{~mm}$ civarındadır. Siirt ilinde en yüksek sıcaklıklar Ağustos ve Eylül aylarında, en düşük sıcaklıklar ise Ocak ve Şubat aylarında yaşanmaktadır. Yıllık ortalama bağıl nem \% 51 olup, en yüksek bağıl nem \% 70 ile Ocak ve Aralık aylarında görülmektedir.

Siirt ilinde; toplam alanın \% 34.96's1 \% 6'dan düşük, $\% \quad 59.53^{\prime} \ddot{\text { ü }} \% \quad 6-30$ arasında eğim değerlerine sahip olup, \% 30'un üzerinde eğimli sahalar sadece ilin \% 5.51'inde görülmektedir. Siirt ilinin yarısından çoğunda yaklaşık \% 65'inde kahverengi orman toprağı bulunur. İl arazisinin yaklaşık \% 90'ında orta, şiddetli ve çok şiddetli erozyon olduğu görülmüştür. Toplam alanının sadece \% 9'luk kısmı I., II. ve III. sınıf kabiliyete sahip alanlardan oluşmakta, \% 85 oranıyla sahanın büyük kısmını çok sığ ve sı̆̆ topraklar teşkil etmektedir. Derin ve çok derin toprakların ise batıda ovalık arazilerde ve vadilerde küçük alanlarda yer alır (Özyazıcı ve ark., 2014).

Siirt ilinde 2014 y1lı verilerine göre (Anonim, 2015c), toplam arazi varlığ1 562.667 hektar olup, mevcut arazi varlığının \% 18.3 'ünde tarım yapılabilmektedir. Ormanlık ve fundalık alan 214.394 ha ile toplam alan içindeki \% 38.1 oranılla en fazla yer kaplarken, çayır ve mera alanı 124.441 ha, tarım dışı arazi miktarı ise 120.938 hektardir (Tablo 1).

Tablo 1 incelendiğinde; en fazla tarım arazisi Kurtalan ilçesinde yer almakta olup, bunu Merkez ilçenin tarım arazisi takip etmektedir. Buna karşılık, çayır ve mera arazisi, tarım dışı arazi ve orman-fundalık alanların en fazla Pervari ilçesinde olduğu görülmektedir. 
Tablo 1. Siirt ilinin kullanım durumuna göre arazi dağılımı (ha) (Anonim, 2015c)

\begin{tabular}{lrrrrr}
\hline İlçeler & Yüzölçümü & Tarım arazisi & $\begin{array}{c}\text { Orman ve fundalık } \\
\text { alan }\end{array}$ & Çayır mera alanı & $\begin{array}{c}\text { Tarıma elverişsiz } \\
\text { alan }\end{array}$ \\
\hline Merkez & 63.549 & 17.351 & 19.414 & 12.542 & 14.241 \\
Tillo & 11.998 & 4.110 & 2.123 & 2.197 & 3.567 \\
Baykan & 48.499 & 7.491 & 22.092 & 9.882 & 9.034 \\
Eruh & 100.440 & 8.388 & 57.768 & 23.062 & 11.220 \\
Kurtalan & 80.422 & 50.399 & 6.624 & 9.908 & 13.489 \\
Pervari & 162.998 & 8.765 & 71.515 & 45.241 & 37.445 \\
Şirvan & 94.799 & 6.390 & 34.858 & 21.608 & 31.942 \\
\hline Toplam & 562.667 & 102.894 & 214.394 & 124.441 & 120.938 \\
\hline Oran & 100.0 & 18.3 & 38.1 & 22.1 & 21.5 \\
\hline
\end{tabular}

Siirt ili tarımsal ürün deseni incelendiğinde (Anonim, 2015c); tarım arazilerinin \% 41.3'ünde hububat ekiminin yapıldığ 1 , bunu \% 23.1 ile meyve dikili alanların takip ettiği görülmektedir. Kırsal kesimde ekim yapılan alanlar ile nadas alanlarının tarım arazisi içindeki payı (\% 16.7) da önemli yer kaplamaktadır. Toplam tarım alanı içerisinde yem bitkilerinin ekiliş alanı ise 7.921 ha olup, oldukça düşük düzeydedir (Tablo 2).
Siirt ilinde yem bitkileri yetiștiriciliği incelendiğinde (Tablo 3) (Anonim, 2015c); yem bitkileri üretimi amaciyla fiğ, korunga, yonca ve silajlık mısır tarımının yaygın olduğu, 41.422 dekar ile en fazla fiğ ekiminin yapıldığı, bunu $25.744,11.125$ ve 919 dekar ile sirasiyla korunga, yonca ve silajlık mısır ekilişinin takip ettiği tespit edilmiştir. İl genelindeki 79.210 dekarlık yem bitkileri tarımının yaklaşık \% 74'ünün Pervari

Tablo 2. Siirt ilinin tarım arazilerinin kullanım durumuna göre sınıflandırılması (Anonim, 2015c)

\begin{tabular}{|c|c|c|c|c|c|c|c|c|c|}
\hline $\begin{array}{l}\text { Tarımsal arazi varlığ } \\
\text { (ha) }\end{array}$ & Merkez & Tillo & Baykan & Eruh & Kurtalan & Pervari & Şirvan & Toplam & $\begin{array}{c}\text { Oran } \\
(\%)\end{array}$ \\
\hline Hububat alanı & 3.200 & 200 & 2.475 & 3.350 & 29.750 & 1.700 & 1.800 & 42.475 & 41.3 \\
\hline $\begin{array}{l}\text { Nadas ve ekim yapılan } \\
\text { kırsal alan }\end{array}$ & 2.600 & 1.500 & 2.500 & 11 & 9.000 & --- & 1.500 & 17.111 & 16.7 \\
\hline $\begin{array}{l}\text { Sebze alan1 } \\
\text { (örtü altı dâhil) }\end{array}$ & 395 & 8 & 150 & 532 & 823 & 65 & 50 & 2.023 & 2.0 \\
\hline Meyve alanı & 9.000 & 2.330 & 1.783 & 3.017 & 4.006 & 1.070 & 2.550 & 23.756 & 3.1 \\
\hline Bağ alanı & 200 & 60 & 450 & 600 & 750 & 60 & 180 & 2.300 & 2.2 \\
\hline Baklagil ekim alanı & 1.100 & --- & 60 & 140 & 3.530 & 20 & 8 & 4.858 & 4.7 \\
\hline $\begin{array}{l}\text { Endüstri bitkileri ekim } \\
\text { alanı }\end{array}$ & 280 & --- & --- & --- & 2.170 & --- & --- & 2.450 & 2.4 \\
\hline Yem bitkileri ekim alanı & 143 & 3 & 107 & 866 & 48 & 5.867 & 887 & 7.921 & 7.7 \\
\hline Toplam & 17.351 & 4.110 & 7.491 & 8.388 & 50.399 & 8.765 & 6.390 & 102.894 & 100.0 \\
\hline
\end{tabular}

Tablo 3. Siirt ili yem bitkileri ekiliș ve üretim durumu (Anonim, 2015c)

\begin{tabular}{lrrrrr}
\hline İlçeler & \multicolumn{5}{c}{ Ekilen alan (da) } \\
\cline { 2 - 6 } & Yonca & Korunga & Fiğ & Silajlık Misır & Toplam \\
\hline Merkez & --- & --- & 809 & 617 & 1.426 \\
Tillo & --- & -- & 29 & --- & \\
Baykan & --- & --- & 1.070 & --- & 1.070 \\
Eruh & 111 & 28 & 8.520 & --- & 8.659 \\
Kurtalan & 101 & --- & 380 & -- & 481 \\
Pervari & 10.192 & 18.761 & 29.420 & 295 & 58.668 \\
Şirvan & 721 & 6.955 & 1.194 & 7 & 8.877 \\
\hline Toplam & 11.125 & 25.744 & 41.422 & 919 & 79.210 \\
\hline Kuru ot üretimi (ton) & 13.350 & 20.595 & 24.853 & 1.379 & 60.177 \\
\hline Kuru ot verimi (kg da $\left.{ }^{-1}\right)$ & 1.200 & 800 & 600 & 1.500 & \\
\hline
\end{tabular}


ilçesinde yapıldı̆̆ 1 , fiğ üretiminin de 29.420 da ile en fazla yine aynı ilçede gerçekleştiği görülmektedir. Yem bitkilerinin kraliçesi diye tabir edilen yoncanın sulu şartlarda birim alandan daha fazla verim alınmasına rağmen, yetiştiriciliği fiğ ve korungadan sonra gelmektedir. Ayrica besleme değeri ve lezzetliliği yüksek, birim alandan fazla yeşil aksam üretmesi ve yem bitkilerine göre maliyeti daha düşük olan silajlık mısır yetiştiriciliğinin ise oldukça düşük düzeyde kaldığı görülmektedir (Tablo 3). Hayvancılığı gelişmiş ülkelerde toplam tarla arazisi içerisinde yem bitkileri ekim alanları ortalama \% 25-30 iken (Semerci ve Kurt, 2006), Siirt'te bu oran \% 7.7 düzeyinde kalmakta ve tarımı gelişmiş ülkelerin ortalamasından oldukça düşük olduğu görülmektedir.

\section{Siirt İli Hayvan Varlığı}

Tablo 4 incelendiğinde, Siirt ili hayvancılık bakımından küçükbaş hayvan yetiştiriciliğine daha fazla yöneldiği görülmektedir. 899.873 küçükbaş hayvan varlığına karşın, 23.300 büyük baş ve 7.528 baş tek tırnaklı olmak üzere toplam 930.701 baş hayvan sayısına sahiptir. Siirt ili bu hayvan varlığı ile Türkiye hayvan varlığının (kümes hayvanları hariç) \% 1.7 'sini oluşturmaktadır. İldeki büyükbaş hayvan varlığının yaklaşık \% 42'si düşük verimli yerli ırklardan oluşmaktadır (Anonim, 2015d).

Tablo 4. Siirt ili hayvan varlığı (Anonim, 2015d)

\begin{tabular}{|c|c|c|c|}
\hline Hayvan türü & $\begin{array}{c}\text { Hayvan } \\
\text { sayis1 } \\
\text { (baș) }\end{array}$ & $\begin{array}{c}\text { Hayvan } \\
\text { birimi }\end{array}$ & $\begin{array}{l}\mathrm{BBHB} \\
\text { değeri* }\end{array}$ \\
\hline & \multicolumn{3}{|c|}{ Büyükbaş } \\
\hline$\overline{\text { Sığır (kültür) }}$ & 4.214 & 1 & 4.214 \\
\hline Sığır (melez) & 9.397 & 0.75 & 7.048 \\
\hline Sığır (yerli) & 9.689 & 0.50 & 4.845 \\
\hline \multirow[t]{2}{*}{ Toplam } & 23.300 & & 16.107 \\
\hline & \multicolumn{3}{|c|}{ Küçükbaş } \\
\hline Koyun (yerli) & 539.515 & 0.10 & 53.952 \\
\hline$\underline{K e c ̧ i ~(k 1 l, ~ t i f t i k)}$ & 360.358 & 0.08 & 28.829 \\
\hline \multirow[t]{2}{*}{ Toplam } & 899.873 & & 82.781 \\
\hline & \multicolumn{3}{|c|}{ Tek tırnaklılar } \\
\hline At, katır, eşek & 7.528 & 0.40 & 3.011 \\
\hline İl toplamı & 930.701 & & 101.899 \\
\hline
\end{tabular}

İlde, 16.107 BBHB'ye eşdeğer büyükbaş hayvan sayısı bulunduğu, bunun 4.214'ünün kültür, 7.048'inin melez ve $4.845^{\prime}$ 'inin ise yerli sığır olduğu görülmektedir. Bununla beraber ilde, 82.781 BBHB'ye eşdeğer miktarda küçükbaş hayvan bulunduğu, bunun 53.952'sinin yerli koyun, 28.829'unun ise k1l ve tiftik keçisinin olduğu tespit edilmiştir. At, katır ve eşekten oluşan tek tırnaklıların BBHB cinsinden değeri ise 3.011 olarak belirlenmiştir (Tablo 4).

\section{Siirt İli Kaba Yem Üretim Durumu}

Tabii halde \% 14'ten daha fazla su içeriğine ya da kuru maddede \% 16'dan daha yüksek ham selüloz içeriğine sahip ve sindirilebilir organik maddeler ve enerji değeri bakımından düşük olan her tür materyal kaba yem olarak tanımlanmaktadır (Akyıldız, 1983; Kılıç, 2000).

Hayvan varlığı kadar önemli diğer bir husus ise bu hayvanların ihtiyaç duydukları kaba yem miktarıdır. Bir BBHB $500 \mathrm{~kg}$ canlı ağırlık olarak kabul edilmektedir. Hayvanların BBHB cinsinden kaba yem ihtiyacının hesaplanmasında; günlük canlı ağırlığının \% 2.5'i kadar kuru ot veya \% 10'u kadar yeşil ot yedirilmesi gerektiği esas alınmaktadır. Bir başka ifade ile $500 \mathrm{~kg}$ canlı ağırlığındaki (1 BBHB) bir hayvanın günlük kuru ot ihtiyacı 12.5 kg'dır (Sayar ve ark., 2010; Çelik ve Şahin Demirbağ, 2013).

Siirt ilinde 23.300 büyükbaş, 899.873 küçükbaş ve 7.528 tek tırnaklı olmak üzere toplam 930.701 adet bulunan hayvan varlığının BBHB değeri 101.899 olarak ortaya çıkmaktadır (Tablo 4). Bu bilgiler doğrultusunda mevcut hayvan varlığının günlük kaliteli kaba yem ihtiyacı 1.274 ton kuru ot, yıllık ise yaklaşık 464.914 ton kuru ottur.

Çayır ve meralar, kaliteli kaba yemin bol ve en ucuz üretildiği alanlar olarak kabul edilmesi nedeni ile gelişmiş ülkelerde, hayvan beslemesinde önemli yer tutmaktadır (Sayar ve ark., 2010). Siirt ilinde 95.240 ha mera, 29.201 ha ise çayır alanı bulunmaktadır (Anonim, 2015c). Günümüzde Güney Doğu Anadolu Bölgesi'ndeki çayırların kuru ot verimlerinin $250-300 \mathrm{~kg} \mathrm{da}^{-1}$, meraların ise 40-45 $\mathrm{kg} \mathrm{da}^{-1}$ arasında değiștiği bildirilmektedir (Anonymous, 2015). Buna göre, çayırların kuru ot verimi $300 \mathrm{~kg} \mathrm{da}^{-1}$ ve meraların ise $45 \mathrm{~kg} \mathrm{da}^{-1}$ esas alındığında; Siirt ili mera alanlarından yaklaşık 42.858 ton, çayır alanından ise 87.603 ton kuru ot elde edilebilmektedir.

Siirt ilinde 2014 yılı verilerine göre, tarla tarımı içerisinde yem bitkilerinin ekilmesi sonucu toplam 60.177 ton kuru ota eşdeğer miktarda kaliteli kaba yem üretimi gerçekleşmiştir (Tablo 3). Yem bitkileri ekilişlerinden elde edilen bu kaba yem miktarı il hayvancılığının ihtiyaç duyduğu toplam kaba yem ihtiyacinın \% 12.9'una denk gelmektedir. İlin çayır ve mera alanları ile tarla tarımı içerisinde ekilen yem bitkilerinden toplam 190.638 ton kuru ot elde edilebilmektedir. Bu kaba yem miktarı, il genelinde hayvanların ihtiyaç duyduğu kaba yemin (464.914 ton) \% 41.0'ını karşılayabilmektedir. Bu duruma göre, Siirt ilinde 
\% 59 oranı ile yaklaşık 274.276 ton kaliteli kaba yem açığı bulunmaktadır.

\section{Siirt İlinde Kaba Yem Üretim Sorunları ve Çözüm Önerileri}

\subsection{Kaba yem üretim sorunları}

Siirt ilinde hayvancılık daha çok doğal çayır ve meralara dayalıdır. Çayır ve mera alanlarının zamansız, bilinçsiz ve otlatma kapasitesinin üzerinde hayvan sayısı ile otlatılması nedeniyle, tahribatı söz konusudur. Yaz aylarındaki düşük yağış oranı, erken başlayan yaz sıcaklıkları ve uzun süren kuraklık gibi iklim koşullarına otlatma baskısı da eklenince, mera alanlarının ot üretimi ve botanik kompozisyondaki iyi cins yem bitkilerinin azalmasina neden olmaktadır. Dolayısıyla, ot üretkenliği az olan meralarda otlayan hayvanların et ve süt verimleri de düşmektedir.

İlde ortaya çıkan kaba yem açığı genellikle anız artıkları, kesif yemlerle ve besleme değeri düşük olan sap ve samandan karşılanmaktadır. Kesif yemler besleme maliyetini arttırdığından dolayı hayvancılık işletmelerinin karlılık oranı düşmektedir. Sap-saman gibi besin değeri düşük olan yemlerle beslenen hayvanlardan elde edilen et ve süt verimi de haliyle düşük olmaktadır.

İl hayvancılığının ihtiyaç duyduğu toplam kaba yemin ancak \% 13'ünün tarla tarımı içerisinde yetiştirilen yem bitkilerinden karşılandı ğ 1 ve yem bitkilerine ayrılan alanın \% 7.7 gibi düşük düzeyde olduğu göz önüne alındığında, yörede yem bitkileri yetiştirme kültürünün oluşmadığı ve yem bitkileri tarımına gereken önemin verilmediği anlaşılmaktadır. Bu durum Kara ve ark. (2009), Sayar ve ark. (2010), Temel ve Şahin (2011) ve Budak (2013) tarafindan yapılan çalışmalarda da vurgulanmıştır.

Yöre hayvancılığı küçük işletmelerden oluşmakta ve bu küçük işletmelerin arazi varlıkları ufak parçalar halindedir. İşletmeler küçük olunca mekanizasyon vb. problemlerden dolayı yem bitkisi ekimi zorlaşmakta veya ekim gerçekleşmemektedir.

2013 yılı verilerine göre, Siirt'te toplam y1llık süt üretimi 60.435 ton olup, süt üretimi içinde en fazla üretim inek sütünde (\% 40.6) yer almakta, bunu \% 30.7 ile koyun sütü ve \% 28.8 ile keçi sütü üretimi izlemektedir. Siirt ili Türkiye süt üretiminin \% $\%$ 0.3'ünü karşılamaktadır (Anonim, 2015e). Mera alanına göre bu rakamlar oldukça düşük kalmaktadır.

\subsection{Kaba yem açığının giderilmesine yönelik çözüm önerileri}

1. Hayvan beslenmesinde büyük önem taşıyan çayır ve meralar bol ve ucuz kaliteli kaba yemin üretildiği alanlardır. Çayır alanlarında, gübreleme, sulama ve yabanc1 ot mücadelesi gibi kültürel tedbirlere önem verilmeli, biçim işlemlerinin çok dipten yapılmaması gerekmektedir.

2. Mera alanlarında ise, otlatma kapasitesi, otlatmaya başlama ve son verme gibi amenajman ilkelerine uyulmalı, oldukça sığ toprak yapısına sahip ve bitki örtüsü zayıflamış bu alanlarda mera ıslah çalışmalarına hız verilmelidir.

3. Gıda Tarım ve Hayvancılık Bakanlığı'nın Hayvancılığı Destekleme Hakkındaki Karar kapsamında suni meraların tesisi de desteklemeye tabidir. $\mathrm{Bu}$ destek kapsamında vejetasyonu zayıflamış ve çıplaklaşmış alanlarda suni mera tesisine gereken önem verilmelidir.

4. Yörede yem bitkileri ekim alanlarının arttırılması ve birim alandan daha fazla miktarda yem bitkisi üretimi yoluna gidilmesi gerekmektedir. $\mathrm{Bu}$ amaçla, nadasa ayrılan alanlarda, nadas+buğday (tahıl) ekim nöbetinin uygulandığı sistemlerde çok yıllık baklagil yem bitkileri (yonca, korunga gibi); ana ürünlerin araziyi boş bıraktığı yaz ve/veya kış aylarında tek yıllık baklagil (fiğ, yem bezelyesi, yem baklası gibi) veya hayvan pancarı gibi yem bitkileri ekim nöbeti sistemlerine alınmalıdır. Bununla birlikte, baklagil yem bitkileri ile kılçıksız brom, otlak ayrığı, mavi ayrık ve koyun yumağı gibi çok yıllık buğdaygil yem bitkileri karışım halinde ekilmeli ve bu konuda üreticiler bilinçlendirilmelidir.

5. Siirt ili topraklarının topoğrafik koşulları nedeniyle arazisinin büyük çoğunluğunun işlemeli tarıma uygun olmayan alanlar olduğu ve bu alanların potansiyel toprak erozyonunun tehdidi altında olduğu göz önüne alındığında; özel bir takım önlemlerle bu alanlar çok yıllık yem bitkileri ile değerlendirilebilinir.

6. Yem bitkileri ve sertifikalı tohumluk destekleme miktarı arttırılarak devam edilmeli ve analiz raporlu tohumluk üretimi destek kapsamına alınmalıdır.

7. Eğitim faaliyetleri ile çiftçilere yem bitkilerinin hayvansal üretimdeki önemi anlatılmalı, teşvik primleri hakkında bilgilendirilmeli ve yem bitkisi ekmeleri özendirilmelidir.

8. Üretimde örgütlü ve dayanışma kültürüne ve alışkanlığına sahip olmayan çiftçilerin birlik kurarak veya kooperatifleşerek güç birliği 
yapmaları sağlanmalı ve bu konudaki bürokratik işlemler kolaylaştırılmalıdır.

9. Süt sığırcılığının beslenmesinde önemli bir yer tutan silajlik misir ve sorgumun ekim alanları arttırılmalı ve yetiştiriciliği yaygınlaştırılmalıdır.

10. Çiftçiler genellikle sürüm, ekim, bakım ve hasat gibi mekanizasyon gerektiren tarımsal faaliyetleri geleneksel yöntemlerle yürütmektedir. Gıda Tarım ve Hayvancılık Bakanlığı tarafından alet-makine desteği projesinin kapsamı genişletilerek, çiftçilerin daha fazla alet ve makineden faydalanmaları sağlanmalıdır.

\section{Sonuçlar}

Siirt'te kaba yem açığının giderilmesi için meralar sslah edilmeli, otlatma sistemleri mera amenajman ilkelerine göre düzenlenmeli ve işlemeli tarıma uygun olmayan arazilerde suni meralar tesis edilmelidir.

Ülkemizde yem bitkileri desteklemelerinin artışına paralel olarak tarla tarımı içerisinde yem bitkilerine ayrılan alan oranı \% 11 seviyesine ulaşmış iken, Siirt ilinde bu oran \% 8 düzeyinde kalmıştır. Tarımı gelişmiş birçok ülke ile kıyaslandığında, gerek ülkemiz açısından gerekse Siirt ili açısından yem bitkileri tarımının istenilen düzeyde olmadığı rahatlıkla anlaşılmaktadır. İlde mevcut kaba yem üretimi toplam kaba yem ihtiyacının yarısına yakı bir kısmını karşılayabilmektedir.

Yem bitkilerinin ekim nöbeti içerisinde yer alması ve nadas uygulamasının yapıldığı yerlerde yem bitkilerinin yetiştirilmesi sağlanarak, tarla ziraatı içerisindeki ekim oranı arttırılmalıdır. Üreticiler, yem bitkileri yetiştiriciliği ve hayvan beslenmesindeki önemi ile yetiştirme teknikleri konusunda bilinçlendirilmeli ve her türlü tarımsal yayım araçlarından yararlandırılmalıdır.

\section{Kaynaklar}

Açıkgöz, E., 2001. Yem Bitkileri. Uludağ Üniversitesi Güçlendirme Vakfi Yayın No: 182, Bursa.

Açıkgöz, E., Hatipoğlu, R., Altınok, S., Sancak, C., Tan, A., Uraz, D., 2005. Yem bitkileri üretimi ve sorunları. Türkiye Ziraat Mühendisliği VI. Teknik Tarım Kongresi, 3-7 Ocak, Ankara, s. 503-518.

Akyıldız, R., 1983. Yemler Bilgisi ve Teknolojisi. Ankara Üniversitesi Ziraat Fakültesi Yayınları No: 868, Ankara.

Alçiçek, A., Kılıç, A., Ayhan, V., Özdoğan, M., 2010. Türkiye'de kaba yem üretimi ve sorunlar1. Türkiye Ziraat Mühendisliği VII. Teknik Kongresi, TMMOB Ziraat Mühendisleri Odas1 (ZMO) 11-15 Ocak, Cilt:2, Ankara, s. 1071-1080.
Altın, M., Gökkuş, A., Koç, A., 2011. Çayır Mera Yönetimi, I. Cilt (Genel İlkeler). T.C. Tarım ve Köyişleri Bakanlığı, Tarımsal Üretim ve Geliştirme Genel Müdürlüğü, Ankara.

Anonim, 2015a. Türkiye İstatistik Kurumu. http://www.tuik.gov.tr/UstMenu.do?metod=temelist (Erişim tarihi: 05.02.2015).

Anonim, 2015b. T.C. Gida Tarım ve Hayvancilık Bakanlığ1, Bitkisel Üretim Genel Müdürlüğü Faaliyetleri, Kasim 2014. http://www.tarim. gov.tr/sgb/Belgeler/SagMenuVeriler/ BUGEM.pdf (Erişim tarihi: 05.02.2015).

Anonim, 2015c. T.C. Siirt Valiliği, Gıda Tarım ve Hayvanc1lık İl Müdürlüğü 2013-2014 Faaliyet Raporu.

Anonim, 2015d. T.C. Gida Tarım ve Hayvancilık Bakanlığı, Strateji Geliştirme Başkanlığı, Tarımsal Yatırımcı Danışma Ofisi, Siirt İli Tarımsal Yatırım Rehberi, Şubat 2015. https://www.tarim.gov.tr/ SGB/TARYAT/Belgeler/il_yatirim_rehberleri/siirt.p df (Erişim tarihi: 07.01.2015).

Anonim, 2015e. Seçilmiş Göstergelerle Siirt 2013. Türkiye İstatistik Kurumu. http://www.tuik.gov.tr/ ilGostergeleri/iller/SIIRT.pdf (Erişim tarihi: $05.01 .2015)$.

Anonymous, 2015. Food and Agriculture Organization of the United Nations (FAO). http://www. fao.org/ag/AGP/AGPC/doc/Counprof/Turkey/Turke y.htm (Erişim tarihi: 03.02.2015).

Budak, F., 2013. Iğdır ili çayır-mera ve yem bitkilerinin durumu, hayvan beslenmesinde önemi. Tarlm Bilimleri Araştırma Dergisi, 6(2): 49-55.

Çelik, A., Şahin Demirbă̆, N., 2013. Türkiye'de Tarımsal Desteklemelerin Yem Bitkileri Ekiliş ve Üretim Üzerine Etkisi. Ankara.

Kara, A., Kadıŏlu, S., Çakal, Ş., Aygün, C., Şeker, H., Taş, N., 2009. Kuzeydoğu Anadolu'da baklagil yem bitkileri tarımı ve sorunları. Alınteri Zirai Bilimler Dergisi, 16(1): 19-32.

K1lıç, A., 2000. Kaba yem üretimi ve sorunları. Türkiye Ziraat Mühendisliği V. Teknik Kongresi, 1. Cilt, 1721 Ocak, Ankara, s. 845-858.

Kuşvuran, A., Nazl1, R.İ., Tans1, V., 2011. Türkiye'de ve Batı Karadeniz Bölgesi'nde çayır-mera alanları, hayvan varlığı ve yem bitkileri tarımının bugünkü durumu. Gaziosmanpaşa Üniversitesi Ziraat Fakültesi Dergisi, 28(2): 21-32.

Özyazıc1, M.A., Dengiz, O., İmamoğlu, A., 2014. Siirt ili bazı arazi ve toprak özelliklerinin coğrafi bilgi sistem analizleriyle değerlendirilmesi. Türkiye Tarımsal Araştırmalar Dergisi, 1(2): 128-137.

Sayar, M.S., Anlarsal, A.E, Başbağ, M., 2010. Güneydoğu Anadolu Bölgesinde yem bitkileri tarımının mevcut durumu sorunları ve çözüm önerileri. Harran Üniversitesi Ziraat Fakültesi Dergisi, 14(2): 59-67.

Semerci, A., Kurt, C., 2006. Türkiye'de yem bitkileri tarımının önemi. Hasad Hayvancılık Dergisi, 21: $42-49$. 
TURAN ve ark.

Temel, S., Şahin, K., 2011. Iğdır ilinde yem bitkilerinin mevcut durumu, sorunları ve çözüm önerileri. Yüzüncü Yll Üniversitesi Tarım Bilimleri Dergisi, 21(1): 64-72.

Yolcu, H., Tan, M., 2008. Ülkemiz yem bitkileri tarımına genel bir bakış. Tarım Bilimleri Dergisi, 14(3): 303-312.
Yulafçı, A., Pul, M., 2005. Samsun ilinde kaba yem üretimini sinırlayan problemlerin belirlenmesi. Gaziosmanpaşa Üniversitesi Ziraat Fakültesi Dergisi, 22(1): 73-80. 